DOI: $10.37190 /$ epe 170214

\author{
ANDRZEJ BIELSKI ${ }^{1}$, WIESŁAW ZYMON ${ }^{1}$
}

\title{
FILTER BEDS SUPPLEMENTED WITH POWDERED ACTIVATED CARBON
}

\begin{abstract}
Various factors influencing adsorption on powdered activated carbon (PAC) used for the removal of organic compounds from water and wastewater have been investigated. Incomplete utilization of adsorption capacity of PAC observed in current technological applications is caused by too short contact times of aqueous solutions with carbon particles and the system configuration (adsorption in volume systems with simultaneous coagulation). A new method has been proposed involving application of PAC into the upper layer of a two-layer filter or a middle layer of a three-layer filter during bed fluidization. The extended contact time between aqueous solutions and PAC increases the amount of adsorbate adsorbed on the surface of activated carbon. A comparative studies conducted on adsorption in both volume and column systems confirmed better utilization of adsorption capacity for PAC applied on a filter bed. Two models of PAC adsorption in transient conditions were developed for volume and column systems. Computer simulations confirmed that the adsorption capacity of PAC may be increased by several times in column systems with respect to the commonly used adsorption with coagulation in volume systems.
\end{abstract}

\section{INTRODUCTION}

Elimination of the organic contaminants from water becomes currently the primary issue discussed in water treatment and industrial wastewater treatment technologies. Organic compounds of both natural and anthropogenic origin are predominant organic pollutants found in water. Their presence cannot only affect odor and taste of water but they may also have a negative impact on the consumer's organism and act as precursors of oxidation by-products. Treatment of surface water in conventional systems with coagulation, filtration, disinfection and sometimes initial or intermediate oxidation does not always eliminate the risks associated with the presence of dissolved organic compounds in the water. Therefore, some additional sorption processes are required during

${ }^{1}$ Department of Environmental Engineering, Cracow University of Technology, 31-155 Cracow, ul. Warszawska 24, corresponding author A. Bielski, e-mail address: abielski@riad.usk.pk.edu.pl 
water or wastewater treatment. Organic compounds in aquatic solutions have different chemical and physicochemical characteristics, depending on hydrogeological conditions, seasons of the year and the quantity and quality of wastewater discharged to surface waters. Their concentrations in water vary from a few to over a dozen grams of dissolved organic carbon (DOC) per cubic meter. The acceptable concentration of DOC in potable water depends on the chemical composition of water. The concentrations of organic compounds in water should be at such a level as to assure: an acceptable taste and odor, a minimal level of toxic substances and a limited synthesis of disinfection byproducts.

The industrial wastewater has their specific organic contaminants such as, e.g., phenols volatile with steam. Concentrations of phenols in wastewater prior its discharge to surface waters should not exceed $0.1 \mathrm{mg} / \mathrm{dm}^{3}$ [1]. Other organic compounds such as natural water pollutants are also present in wastewater. Removal of phenols is usually combined with a simultaneous removal of other organic compounds; they can be removed by adsorption on activated carbon, essentially, by two methods. The former uses powdered activated carbon (PAC) in volume processes (e.g., in the course of coagulation) while the latter uses particulate or granular activated carbon in filtration columns. Using PAC is usually preferred if there are occasional threats involving possible violation of drinking water standards or effluent discharge standards [2-4].

Different applications of PAC to remove natural organic compounds and THM precursors from water were analyzed elsewhere [4-11]. Based on the literature reports, it was concluded that removal of dissolved organic substances (determined as DOC) and THM precursors depends on many factors such as properties of the discharged substances, their concentrations, type of carbon, process configuration and others. The doses of PAC used in technical applications varied from tens to several hundred of grams per cubic meter.

\section{FACTORS AFFECTING PAC ADSORPTION EFFICIENCY}

\subsection{STATICS OF THE ADSORPTION PROCESS}

PAC and its dose required for removal of pollutants from aqueous solutions is selected based on adsorption isotherms. Natural waters treated for municipalities or treated wastewaters are mixtures of organic compounds at various concentrations and with different affinity to a sorbent surface. Therefore, the integrated pollutant indicators such as: dissolved organic carbon (DOC), absorbance at $254 \mathrm{~nm}(A)$ or concentrations of specific compounds have been introduced to natural waters and wastewater analysis. There is a considerable difference in adsorption capacities with respect to DOC and absorbance at $254 \mathrm{~nm}$. 
Szlachta and Adamski [12] determined the maximum adsorption capacities for natural water based on PAC analysis and approximation of the results with the Langmuir isotherm. The adsorption capacities calculated in relation to DOC and UV absorption at $254 \mathrm{~nm}$ were $0.066-0.040 \mathrm{~g} \mathrm{C} / \mathrm{g}$ PAC and $0.26-1.2 \mathrm{~m}^{3} /(\mathrm{m} \cdot \mathrm{g}$ PAC), respectively. The former values refer to water after coagulation while the latter to raw water. It should be noted that the values refer to the DOC concentrations above $5 \mathrm{~g} \mathrm{C} / \mathrm{m}^{3}$ and $\mathrm{UV}$ absorbance at $254 \mathrm{~nm}$ over $10 \mathrm{~m}^{-1}$. Low equilibrium concentrations are associated with a low adsorption of organic material on carbon. The adsorption isotherms for particular pollutants that are removed from aqueous solutions are necessary to determine adsorption process parameters. The process statics shows that low equilibrium concentrations of compounds removed from water and identified as DOC at $1-2 \mathrm{~g} \mathrm{C} / \mathrm{m}^{3}$ or UV absorbance in the range of $1-3 \mathrm{~m}^{-1}$, requires relatively high PAC doses while its adsorption capacity is not fully utilized.

Therefore, a removal of, e.g., disinfection by-products with $\mathrm{PAC}$ requires from tens to several hundred grams of $\mathrm{PAC} / \mathrm{m}^{3}$, depending on water characteristic $[4,6,10,11]$. Reduction of DOC concentrations in water in static conditions by $1 \mathrm{~g} \mathrm{C} / \mathrm{m}^{3}$ requires doses of 20-40 g PAC $/ \mathrm{m}^{3}$. PAC adsorption capacities for the phenol equilibrium concentrations of $0.1 \mathrm{~g} / \mathrm{m}^{3}$ are a few $\mathrm{mg}$ of phenol/g of PAC, for systems with no other adsorbates. The removal of $1 \mathrm{~g}$ of phenol from $1 \mathrm{~m}^{3}$ requires tens of grams of $\mathrm{PAC} / \mathrm{m}^{3}$. A similar problem is associated with removal of THM precursors.

\subsection{KINETICS OF ADSORPTION ON PAC}

The overall adsorption rate is determined by its slowest step [16], i.e., by diffusion of pollutants within the carbon pores. Therefore, adsorption kinetics is related to the path that the particles take inside the carbon pores. That path is determined by a size of PAC particles [2]. The overall PAC adsorption rate depends mainly on a pollutant transport within PAC grains, and also on its particle size distribution.

The time required to reach equilibrium is related to, i.e., a difference between the solution concentration and the equilibrium concentration, which results from an adsorption isotherm. Utilization of a PAC adsorption capacity depends on a contact time between carbon and the aqueous solution [13]. Dynamic adsorption isotherms can be determined based on changes in pollutant concentrations during the adsorption process at a given PAC dose. They describe the amounts of adsorbed substance from the solution after a given contact time. Masses of adsorbate after $15 \mathrm{~min}$ for coagulation with simultaneous PAC adsorption for DOC are $0.015-0028 \mathrm{~g} \mathrm{C} / \mathrm{g}$ PAC [14] while the average remaining concentrations in solution are $3.0 \mathrm{~g} \mathrm{C} / \mathrm{m}^{3}$. Removal of $1 \mathrm{~g}$ of DOC from $1 \mathrm{~m}^{3}$ of water requires above $50 \mathrm{~g} \mathrm{PAC} / \mathrm{m}^{3}$.

\subsection{ADSORPTION PROCESS}

Tests on the use of PAC imitated an ideal process observed in plug-flow reactors without dispersion. In real-life conditions, the process takes place in continuous flow 
reactors with incomplete mixing or in tubular reactors with axial dispersion. In such units, some PAC particles face shorter detention times than the average calculated detention time so the contact time for some parts of the sorbent is also shorter. A shorter contact time causes a decrease of the PAC adsorption and thereby the degree of its utilization. In real-life conditions, utilization of PAC adsorption capacity may be significantly lower than during the initial technological tests due to the different nature of the system operation in a full-scale conditions, if compared to a laboratory units, working in a bench mode. In the process with simultaneous coagulation, reduction of PAC adsorption is observed due to possible adsorption of coagulant polymers on carbon, longer mass transport associated with the presence of carbon particles inside flocks, adsorption of compounds that should have been removed during sole coagulation.

PAC adsorption can be carried out by adding PAC to water after its coagulation and sedimentation, and prior filtration [15]. Carbon captured in a filter bed improves the removal of organic compounds during the filtration process; such process conditions increase also the efficiency of carbon utilization.

\section{NEW CONCEPT OF PAC APPLICATION DURING FILTRATION}

The proposed method involves the use of PAC for adsorption of pollutants remaining in water after coagulation and sedimentation. In this method, two- or three-layer filter beds should be used. In a two-layer filter bed, PAC is applied to the top layer (e.g., anthracite) during its fluidization, at the end of a backwashing phase. Once the activated carbon has been introduced, backwash water is turned off and PAC is embedded within the anthracite bed. A sand layer protects the system against the carbon particles wash-out. Removal of solids and adsorption of dissolved compounds onto PAC takes place during the filtration process. A filter backwash frequency will depend on exhaustion of PAC adsorption capacity. During regeneration of the filter, backwash water with PAC is collected in a separate tank. Because the PAC adsorption capacity is usually not fully utilized during filtration, it is possible to further utilize it during coagulation and to enhance the coagulation process itself. In order to determine whether it is feasible to operate the adsorption system according to the given concept, a series of test studies were conducted.

\section{EXPERIMENTAL}

\subsection{ADSORPTION IN STATIC CONDITIONS}

Samples of natural water from the Rudawa river (water A) were tested. The river flows from the Jurassic massif of the valleys located near Kraków and then passes 
through the plains used mainly for agriculture. The river water contains numerous organic compounds of both natural and anthropogenic origin as well as humic substances responsible for a reddish color of water (and the river name). The raw water parameters were: turbidity $21.0 \mathrm{NTU}$, $\mathrm{pH} 7.6$, alkalinity $190 \mathrm{~g} \mathrm{CaCO}_{3} / \mathrm{m}^{3}$, dissolved oxygen $7.9 \mathrm{~g}$ $\mathrm{O}_{2} / \mathrm{m}^{3}$, BOD $3.9 \mathrm{~g} \mathrm{O}_{2} / \mathrm{m}^{3}$, and DOC $=3.9 \mathrm{~g} \mathrm{C}^{3} \mathrm{~m}^{3}$, initial absorbance $\mathrm{UV}_{254} \mathrm{~mm} 7.2 \mathrm{~m}^{-1}$ after coagulation and sedimentation.

In the following studies tap water samples (water B) were used. The tap water quality parameters were: turbidity $0.1 \mathrm{NTU}, \mathrm{pH} 7.4$, alkalinity $140 \mathrm{~g} \mathrm{CaCO}_{3} / \mathrm{m}^{3}$, dissolved oxygen $8.0 \mathrm{~g} \mathrm{O}_{2} / \mathrm{m}^{3}$, DOC $1.9 \mathrm{~g} \mathrm{C} / \mathrm{m}^{3}$, and initial absorbance $\mathrm{UV}_{254 \mathrm{~mm}} 3.0 \mathrm{~m}^{-1}$. Similar tests were also conducted on synthetic wastewater (water $\mathrm{C}$ ) with a phenol concentration of $1.15 \mathrm{~g} / \mathrm{m}^{3}$.

Natural water was coagulated with a coagulant Flokor 1.2a while adsorption was carried out on powdered activated carbon AKPA 22 [19]. Absorbance was measured with the spectrophotometer Specord 200 Plus, manufactured by Analytikjena. Phenol concentrations were measured by the colorimetric method using 4-aminoantipyrine with the spectrophotometer Specord 200 Plus.

Removal of pollutants from river water A using PAC adsorption. Natural river water (A) was subject to coagulation tests to determine the dose of Flokor 1.2a. Water was coagulated with a coagulant dose of $2 \mathrm{~g} \mathrm{Al} / \mathrm{m}^{3}$ and let settle for $0.5 \mathrm{~h}$. Turbidity of water after coagulation and sedimentation was $1.2 \mathrm{NTU}$ and absorbance at $254 \mathrm{~nm}$ was $7.2 \mathrm{~m}^{-1}$. Then water samples, each of $1 \mathrm{dm}^{3}$ in volume, were poured into 6 beakers and PAC was added; the doses of PAC were: $20,40,60,80,100$ and $120 \mathrm{~g} / \mathrm{m}^{3}$. The samples were stirred at a velocity gradient of $G=62 \mathrm{~s}^{-1}$. Next, after $0.5,2$ and $24 \mathrm{~h}$ of sedimentation UV absorbance at $254 \mathrm{~nm}$ was determined in all samples.

Removal of pollutants from tap water B using PAC adsorption. Tap water (B) samples, each of $1 \mathrm{dm}^{3}$ in volume, were poured into three beakers. Then PAC was added to the beakers at the doses of 20,40 and $60 \mathrm{~g} / \mathrm{m}^{3}$. Then the procedure was similar as for water A samples.

Phenol removal from wastewater (water C). Synthetic wastewater was prepared by adding phenol to tap water samples. The initial phenol concentration in wastewater was $1.15 \mathrm{~g} / \mathrm{m}^{3}$ and UV absorbance at $254 \mathrm{~nm}$ was $3.47 \mathrm{~m}^{-1}$. Wastewater samples, each $1 \mathrm{dm}^{3}$ in volume, were poured into four beakers and then PAC doses in the range of 40-148 g/m were added to the samples. After $0.5 \mathrm{~h}$, the samples were filtered, their UV absorbances were measured and concentrations of phenol in the filtrate determined.

\subsection{ADSORPTION IN DYNAMIC CONDITIONS}

Water samples A, B and C were used during the studies on adsorption in dynamic conditions. The study was carried out in a column $0.035 \mathrm{~m}$ in diameter. The bottom of the column was filled with gravel (height $0.23 \mathrm{~m}$ ) on which a layer of sand was placed 
with the following sand parameters: particle diameter $d_{10} 0.72 \mathrm{~mm}$, the coefficient of uniformity $d_{60} / d_{10} 1.6$, height $0.37 \mathrm{~m}$. Above the sand, an anthracite layer with particle diameters of 1.2-2.4 mm $0.38 \mathrm{~m}$ high was placed. A set of valves allowed filtrate discharge and filter backwashing. The filter worked in a downflow mode and water was supplied by a dosing pump with a variable capacity. The adsorption bed was prepared by injection of a PAC suspension into the anthracite layer during bed fluidization. After sorbent slurry injection, water supply was cut off to settle the anthracite bed with PAC. The water level over the filter bed was slowly stabilized down to the initial operation level. Once the filter bed was prepared, water was pumped to the unit. During filtration, the flow rate of water was measured and samples were taken for analysis.

Removal of pollutants in column adsorption. Natural surface water A was used in the experiments. The water was coagulated with a dose of $2 \mathrm{~g} \mathrm{Al} / \mathrm{m}^{3}$ of Flokor 1,2a. Decanted water was stored in a reservoir $0.150 \mathrm{~m}^{3}$ in volume; water turbidity was 1.4 NTU and UV absorbance at $254 \mathrm{~nm}$ was $7.2 \mathrm{~m}^{-1}$. In the following studies the tap water B was used with an initial UV absorbance at $254 \mathrm{~nm}$ of $3.0 \mathrm{~m}^{-1}$. Similar studies were also performed with water containing phenol (C); the initial phenol concentration was $1.15 \mathrm{~g} / \mathrm{m}^{3}$ and UV absorbance at $254 \mathrm{~nm}$ was $3.47 \mathrm{~m}^{-1}$. All water samples were pumped to the filter at a rate assuring the filtration velocity of $6.0 \mathrm{~m} / \mathrm{h}$ calculated for an empty bed. The filter bed, as described above, was enriched with $3 \mathrm{~g}$ of PAC. In the filter effluent, UV absorbance A at $254 \mathrm{~nm}$ was determined in all samples while in water $\mathrm{C}$ phenol concentrations were also measured in function of time. The column was in operation for $12.5 \mathrm{~h}$ (water A), $10 \mathrm{~h}$ (water B) and $4.33 \mathrm{~h}$ (water C).

\section{DISCUSSION OF THE RESULTS}

\subsection{ADSORPTION IN STATIC CONDITIONS}

Studies on adsorption of pollutants from a river water A at different PAC doses and different process times have shown that differences in absorbances decrease along with an increasing dose of PAC (Fig. 1).

Based on the adsorption results for natural water samples A, amount of adsorbate removed onto PAC was determined depending on concentrations of compounds removed in the aqueous solution (Fig. 2). It was determined as a difference between absorbance before and after adsorption and related to a sorbent dose. Plots of dynamic adsorption of the water sorbent system, obtained for different adsorption times, may be presented as linear functions (Henry's isotherm, dynamic adsorption isotherms). High squares of correlation coefficients $\left(R^{2}\right.$, Fig. 2) were obtained, confirming a good fit between theoretical and experimental data. Similar plots can also be obtained based on the kinetic model of volume adsorption (1)-(3) for suitable value of parameters: $\Gamma, k a_{m}$ 
(Fig. 3). Parameters $\Gamma$ of Henry's isotherm have, in practice, the same values as the slopes of straight lines in Fig. 2. It means that dynamic adsorption plots in the system can be represented by Henry's isotherm for each adsorption time.

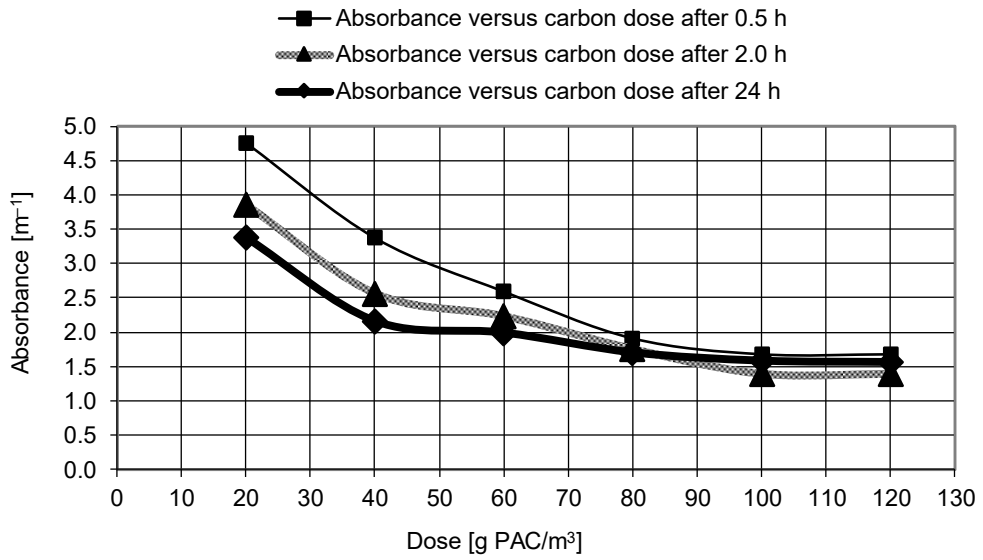

Fig. 1. Absorbance $(254 \mathrm{~nm})$ vs. PAC doses for various contact times (samples A from the Rudawa River after coagulation and sedimentation, initial absorbance $7.2 \mathrm{~m}^{-1}$ )

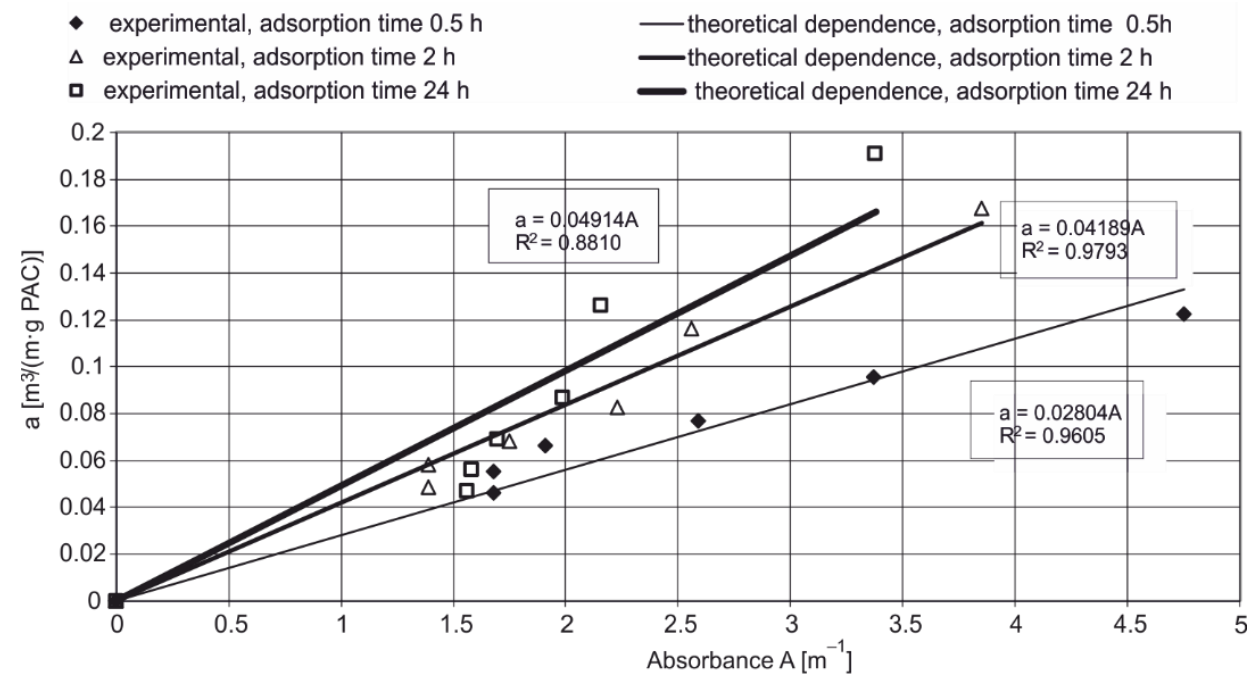

Fig. 2. Amount of adsorbate removed onto PAC (a) vs. UV absorbance at $254 \mathrm{~nm}(A)$ after various adsorption times (initial absorbance $7.2 \mathrm{~m}^{-1}$ )

Based on the slopes of linear functions, it may be concluded that after $0.5 \mathrm{~h}$ adsorption around $57 \%$ of PAC adsorption capacity was utilized compared to the state of the system after $24 \mathrm{~h}$ adsorption (Fig. 2). Longer contact times (up to $2 \mathrm{~h}$ ) resulted in an increase in utilization of adsorption capacity up to $85 \%$ (Fig. 2). The results indicate 
that real-life adsorption times (15-30 min) used in volume systems are too short to effectively utilize sorbent adsorption capacity.

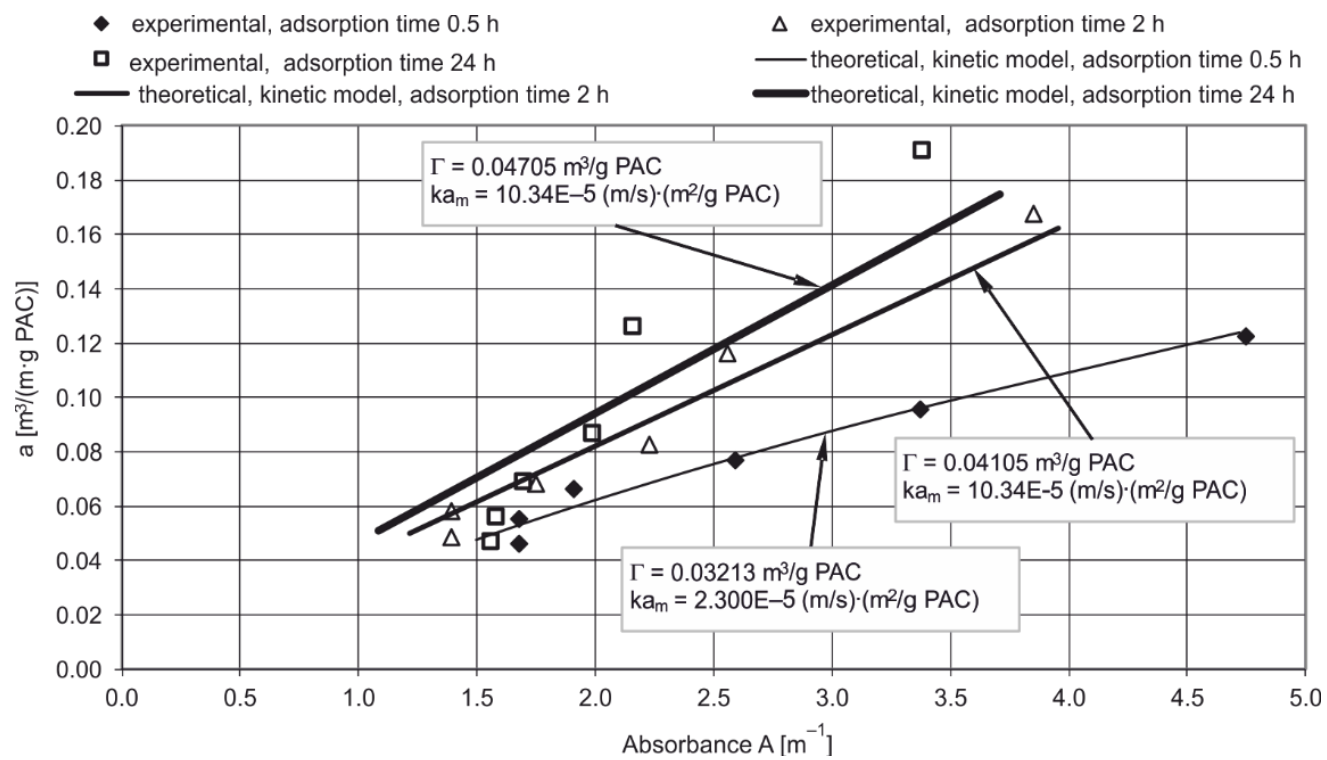

Fig. 3. Dynamic adsorption plots representing amount of adsorbate removed onto PAC $(a)$ vs. UV absorbance at $254 \mathrm{~nm}(A)$ after various adsorption times (initial absorbance $7.2 \mathrm{~m}^{-1}$ )

$\Delta \quad \mathrm{a}\left[\mathrm{m} 3 /\left(\mathrm{m}^{*} \mathrm{~g} P A C\right)\right]$, adsorption time $0.5 \mathrm{~h}$

$\diamond \quad a\left[\mathrm{~m} 3 /\left(\mathrm{m}^{*} \mathrm{~g} P A C\right)\right]$, adsorption time $2.5 \mathrm{~h}$

- $a\left[m 3 /\left(m^{*} g P A C\right)\right]$, adsorption time $24 \mathrm{~h}$
- a theoretical, adsorption time $0.5 \mathrm{~h}$

-a theoretical, adsorption time $2.5 \mathrm{~h}$

a theoretical, adsorption time $24 \mathrm{~h}$

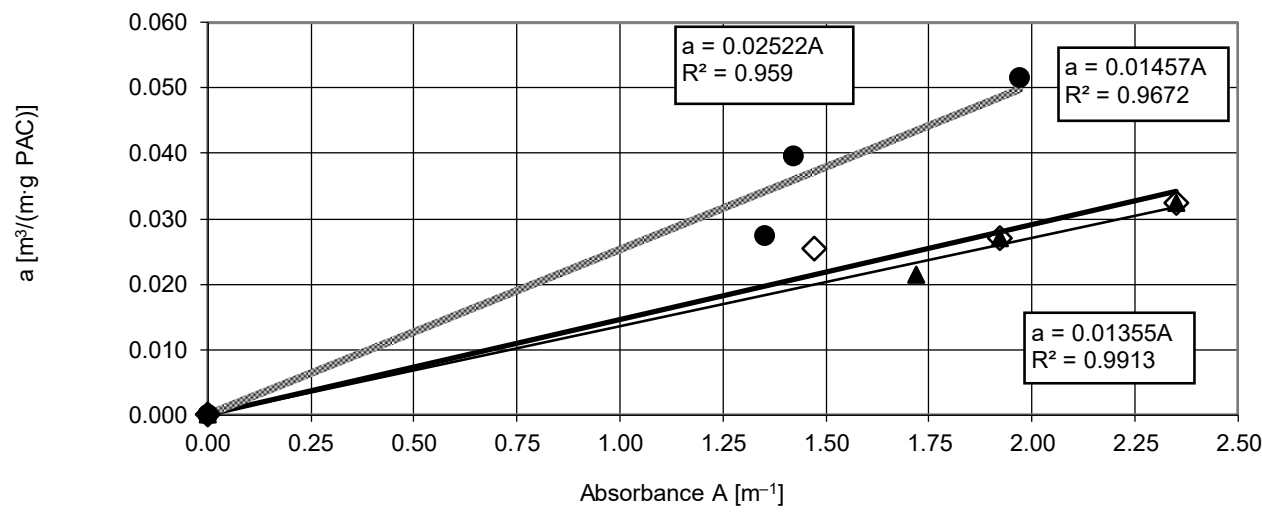

Fig. 4. Amount of adsorbate removed onto PAC (a) vs. UV absorbance at $254 \mathrm{~nm}(A)$ after various adsorption times (tap water, initial absorbance $3.0 \mathrm{~m}^{-1}$ ) 
Figure 4 presents dynamic adsorption plots of the water sorbent system (dynamic adsorption isotherms) describing a relationship between the amount of compounds identified by UV absorbance removed onto PAC and their absorbance in water B. High squares of the correlation coefficients $\left(R^{2}\right.$, Fig. 4$)$ were obtained, which assures a good fit between theoretical and experimental data. Adsorbed amounts after $0.5 \mathrm{~h}$ and $2.5 \mathrm{~h}$ are very similar but their values significantly increase after $24 \mathrm{~h}$ (Fig. 4). Based on the data for $0.5 \mathrm{~h}$ and $2.5 \mathrm{~h}$, it may be stated that respective adsorption quantities amounted to about $55 \%$ of adsorption capacity obtained after $24 \mathrm{~h}$.

A experimental, adsorption time $0.5 \mathrm{~h}$

$\diamond$ experimental, adsorption time $2.5 \mathrm{~h}$

- experimental, adsorption time $24 \mathrm{~h}$
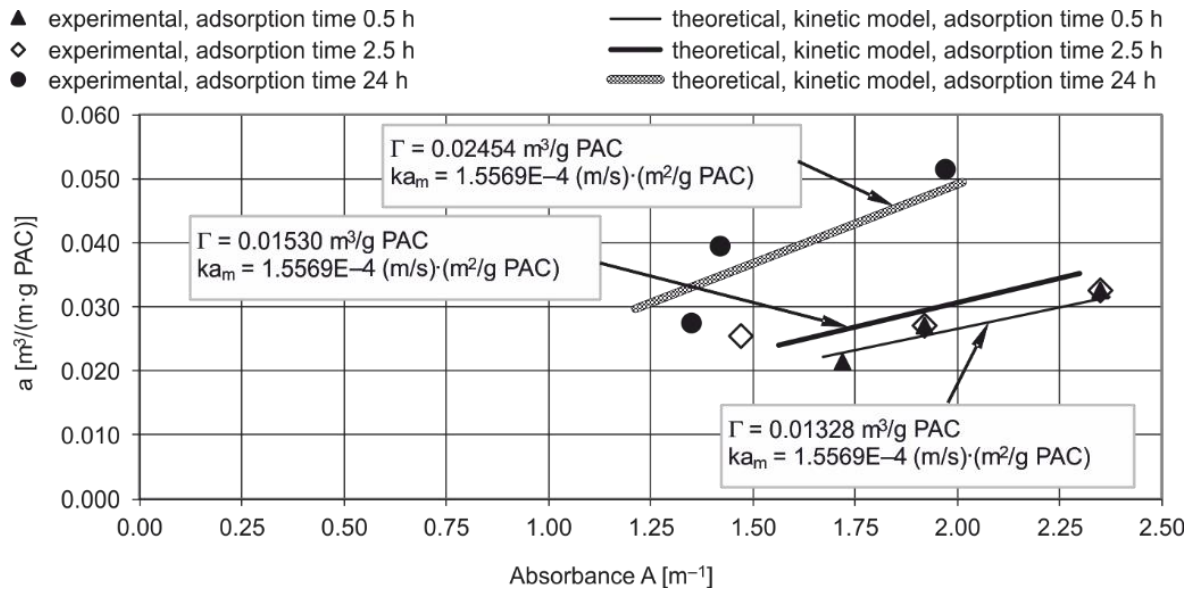

Fig. 5. Dynamic adsorption isotherms representing amount of adsorbate removed onto PAC $(a)$ vs. UV absorbance at $254 \mathrm{~nm}(A)$ after various adsorption times (tap water, initial absorbance $3.0 \mathrm{~m}^{-1}$ )

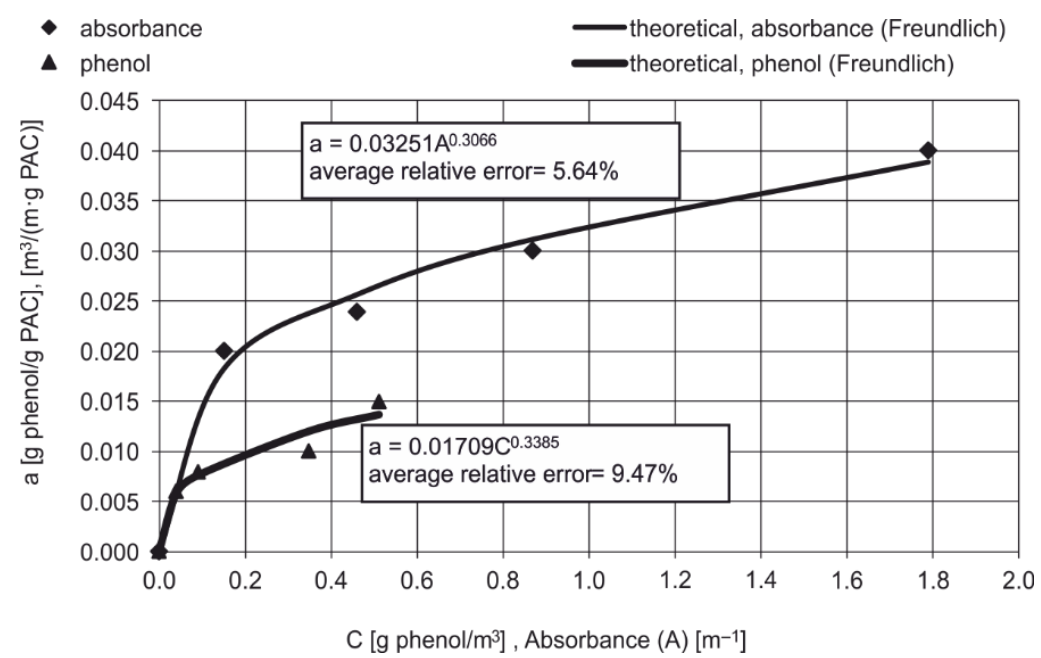

Fig. 6. Amount of adsorbate removed onto PAC ( $a$ ) vs. UV absorbance at $254 \mathrm{~nm}(A)$ of the phenol solution and phenol after $0.5 \mathrm{~h}$ adsorption 
Similar plots can also be obtained based on the kinetic model of volume adsorption (Eqs. (1)-(3)) for suitable values of parameters $\Gamma$ and $k_{a m}$ (Fig. 5). Parameters $\Gamma$ of Henry's isotherm have, in practice, the same values as the slopes of the straight lines in Fig. 4. This proves that dynamic adsorption plots in the system can be described by Henry's isotherm for each adsorption time, respectively. Different values of $\Gamma$ parameters (Figs. 3 and 5) indicate the presence of many organic substances with different affinities for PAC in water A and B.

Figure 6 presents the relationships between the amount of adsorbate removed onto PAC, absorbance and phenol concentrations in water $\mathrm{C}$. The results were approximated with the Freundlich equation. The dynamic adsorption isotherm of phenol, determined after $0.5 \mathrm{~h}$ study, was used in the comparative analysis of adsorption in both column and volume systems. Organic compounds, also present in the tap water used for wastewater preparation, are being adsorbed along with phenol. They may have an inhibiting effect on phenol adsorption. A static analysis was performed to compare the adsorption effects with the results obtained during a modified filtration and adsorption in the column system.

\subsection{DISCUSSION ON ADSORPTION IN DYNAMIC CONDITIONS}

During a column operation with water A, a continuous increase of absorbance was observed from 0 to $4.49 \mathrm{~m}^{-1}$. Time dependences of absorbance are presented in Fig. 7 (dots). A filtration output, calculated on the basis of the operating data, was $75 \mathrm{~m}^{3}$ of the filtrate per $1 \mathrm{~m}^{2}$ of the column cross section area. The average absorbance (per a cycle) in the filter effluent was determined based on the integral average of changes of absorbance in time; the value was $2.40 \mathrm{~m}^{-1}$ (Table 1).

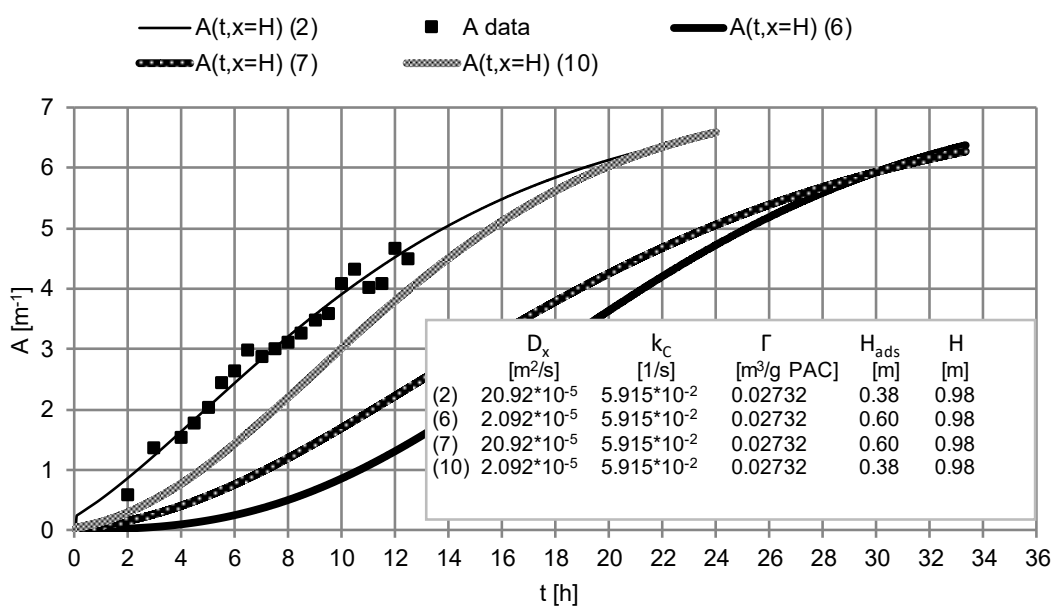

Fig. 7. Time dependences of absorbance $A$ at $254 \mathrm{~nm}$ representing organic compounds in the filtrate (water A) 
When water B was fed to the column, a continuous increase of absorbance was observed from 0 to $1.14 \mathrm{~m}^{-1}$ (dots in Fig. 8). The filtration output, calculated on the basis of the operating data, was $60 \mathrm{~m}^{3}$ of the filtrate per $1 \mathrm{~m}^{2}$ of the column cross section area. The average absorbance (per a cycle) in the filter effluent, $0.55 \mathrm{~m}^{-1}$, was determined based on the integral average of changes of absorbance in time (Table 1).

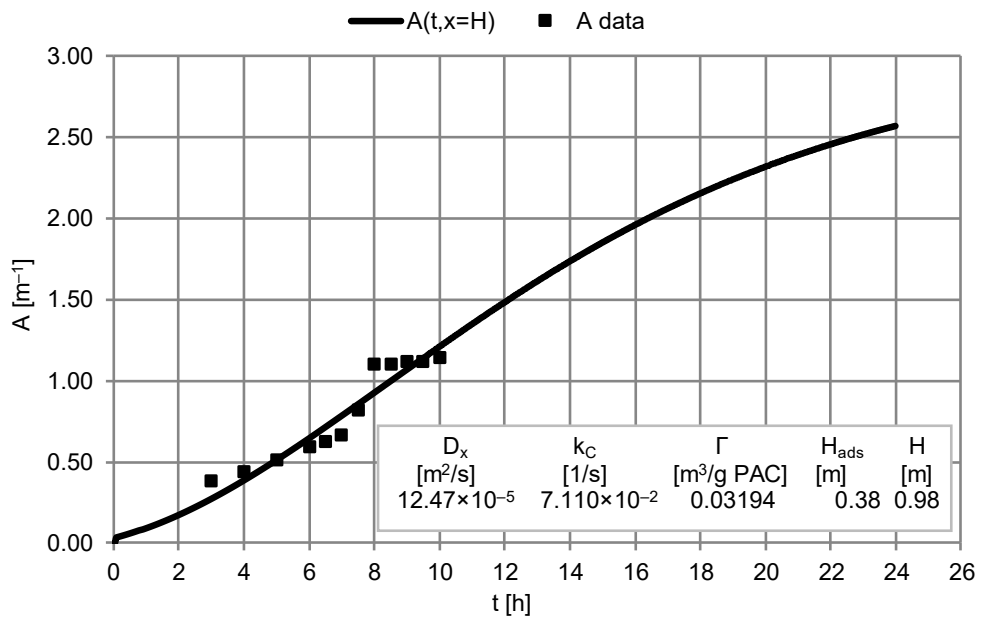

Fig. 8. Time dependences of absorbance $A$ at $254 \mathrm{~nm}$ of organic compounds in the filtrate (water B)

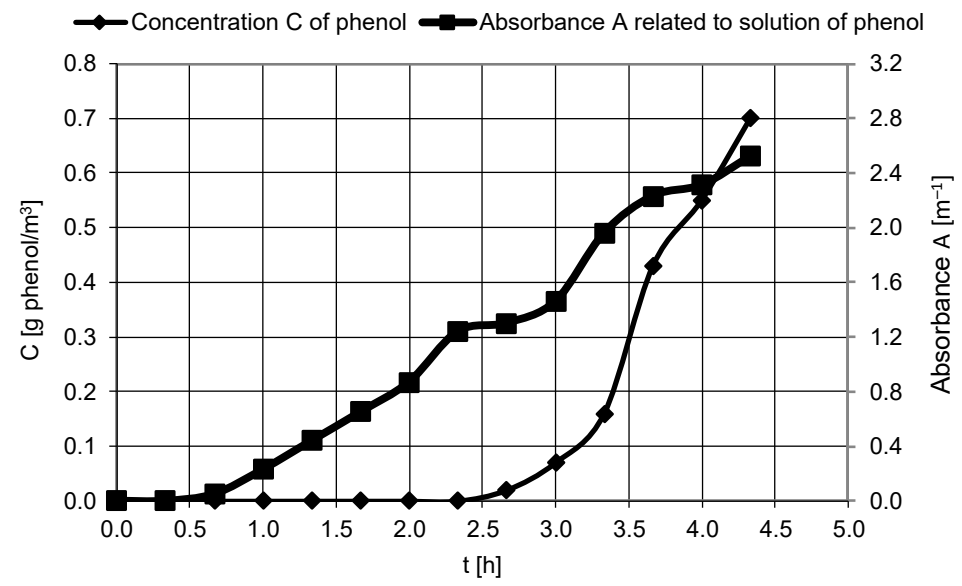

Fig. 9. Time dependences of the concentration $C$ of phenol and absorbance $A$ at $254 \mathrm{~nm}$ of organic compounds in the filtrate (water C)

When water $\mathrm{C}$ with phenol was fed to the column, a continuous increase of both absorbance and phenol concentration was observed; they changed from $0 \mathrm{~m}^{-1}$ to $2.52 \mathrm{~m}^{-1}$, 
and from 0 to $0.7 \mathrm{~g} / \mathrm{m}^{3}$, respectively (Fig. 9). The filtration output, calculated from the operating data, was $26 \mathrm{~m}^{3}$ of the filtrate per $1 \mathrm{~m}^{2}$ of the column cross section area. The average phenol concentration (per a cycle) in the filter effluent was determined based on the integral average of changes of concentration in time; its value was $0.10 \mathrm{~g} / \mathrm{m}^{3}$ (Table 1).

Table 1

Technological effects of adsorption on PAC in column and volume systems

\begin{tabular}{|l|c|c|c|c|}
\hline Medium & $\begin{array}{c}A \text { average } \\
\text { or phenol } \\
\text { concentration } \\
\text { in the filtrate }\end{array}$ & $\begin{array}{c}a_{1} \\
\text { in a column system }\end{array}$ & $\begin{array}{c}a_{2} \\
\text { in a volume system }\end{array}$ & $a_{1} / a_{2}$ \\
\hline Water A & $2.40 \mathrm{~m}^{-1}$ & $0.113 \mathrm{~m}^{3} /(\mathrm{g} \cdot \mathrm{m})$ & $0.067 \mathrm{~m}^{3} /(\mathrm{g} \cdot \mathrm{m})$ & 1.7 \\
\hline Water B & $0.55 \mathrm{~m}^{-1}$ & $0.047 \mathrm{~m}^{3} /(\mathrm{g} \cdot \mathrm{m})$ & $0.016 \mathrm{~m} / 3 / \mathrm{g} \cdot \mathrm{m})$ & 2.9 \\
\hline Wastewater & $0.10 \mathrm{~g}$ of phenol $/ \mathrm{m}^{3}$ & $0.032 \mathrm{~g} \mathrm{phenol} / \mathrm{g} \mathrm{PAC}$ & $0.0078 \mathrm{~g} \mathrm{phenol} / \mathrm{g} \mathrm{PAC}$ & 4.1 \\
\hline
\end{tabular}

\section{TECHNOLOGICAL EFFECTS}

The measurements of absorbance enabled determination of the amount of organic compounds removed in the filter and found in the filter effluent during a filtration cycle. This way the average amount of adsorbate removed onto PAC in a column system could be determined (Table 1). Based on dynamic isotherms (adsorption time $0.5 \mathrm{~h}$ ), PAC adsorption efficiencies in volume systems with adsorption following coagulation and sedimentation were determined (Table 1). They were established for the conditions, when the average absorbance over time in the column effluent was equal to absorbance after $0.5 \mathrm{~h}$ of adsorption in volume systems. The results (Table 1 ) for both water A and B show that sorbent utilization is about 1.7 to 2.9 times greater in the column system than in volume systems.

A similar analysis was done for phenol and the concentration of $0.1 \mathrm{~g} / \mathrm{m}^{3}$ was assumed as a comparative concentration for each configuration. In the column system, sorbent utilization was approximately 4 times greater than in volume systems (Table 1).

\section{ADSORPTION MODELS}

Models described in this section refer to the concentration of the adsorbate $C$ in the liquid phase. The amount of dissolved organic matter is measured using UV absorbance at the wavelength of $254 \mathrm{~nm}$. The absorbance is a measure of the amount of dissolved substances and is proportional to $C$. Therefore, the described models also apply to the absorbance $A$ and $C$ in the following equations can be replaced by $A$. 


\subsection{VOLUME ADSORPTION}

The mass transfer rate between the liquid and the sorbent in a volume system can be described by a set of equations [16-18]:

$$
\begin{gathered}
\frac{d C}{d t} \varepsilon_{m}=-k a_{m} D \frac{\rho_{w}}{\rho_{u}}\left(C-C_{i}\right) \\
\frac{d a}{d t}\left(1-\varepsilon_{m}\right)=k a_{m} D \frac{1}{\rho_{u}}\left(C-C_{i}\right)
\end{gathered}
$$

where: $C$ - adsorbate concentration, $\mathrm{g} / \mathrm{m}^{3}$ of water, $C_{i}$ - equilibrium concentration, $\mathrm{g} / \mathrm{m}^{3}$ of water, $k$ - mass transfer rate constant through the phase boundary water-sorbent, $\mathrm{m} / \mathrm{s}, a_{m}$ - specific surface area of the sorbent, $\mathrm{m}^{2} / \mathrm{g}, D$ - sorbent dose, $\mathrm{g} / \mathrm{m}^{3}, \rho_{w}$ - water density $\left(10^{6} \mathrm{~g} / \mathrm{m}^{3}\right), \rho_{u}$ - system density, $\mathrm{g} / \mathrm{m}^{3}, \varepsilon_{m}$ - mass fraction of water in the system, $a$ - mass of adsorbate removed onto the adsorbent, $\mathrm{g} / \mathrm{g}, t$ - time, $\mathrm{s}$.

A relationship between the equilibrium concentration $C_{i}$ and the actual amount of adsorbate removed results from the adsorption isotherm:

- for Henry's isotherm:

$$
C_{i}=\frac{a}{\Gamma}
$$

- for the Langmuir's isotherm:

$$
C_{i}=\frac{a b}{a_{\max }-a}
$$

where: $\Gamma$ - Henry's coefficient, $\mathrm{m}^{3}$ of water/g of sorben, $a_{\max }$ - maximum adsorption capacity (the Langmuir's isotherm asymptote), $\mathrm{g} / \mathrm{g}, b-\mathrm{a}$ constant, $\mathrm{g} / \mathrm{m}^{3}$ of water.

For the adsorption equilibrium be described with Henry's isotherm, an analytical solution of Eqs. (1) and (2) exists. Describing the equilibrium concentration $C_{i}$ with Eq. (3), the solution of Eqs. (1) and (2) for the initial condition:

$$
C(t=0)=C_{0}
$$

is as follows:

$$
C=\frac{\beta}{\omega}+\left(C_{0}-\frac{\beta}{\omega}\right) \exp (-\alpha \omega t)
$$


in which:

$$
\begin{gathered}
\alpha=k a_{m} D \frac{\rho_{w}}{\rho_{u} \varepsilon_{m}} \\
\beta=\frac{a_{0}}{\Gamma}+\frac{\varepsilon_{m}}{\rho_{w}\left(1-\varepsilon_{m}\right)} \times \frac{C_{0}}{\Gamma} \\
\omega=1+\frac{\varepsilon_{m}}{\rho_{w}\left(1-\varepsilon_{m}\right)} \times \frac{1}{\Gamma}
\end{gathered}
$$

Equation (6) has been used to determine the product $k a_{m}$, which represents a replacement constant of the adsorbate transport rate through a water-sorbent interface in the hydrodynamic conditions, for the particulate sorbent. To determine the parameter $\alpha$ (Eq. (7)), mass of the introduced sorbent per a unit volume of water instead of per a unit volume of the water-sorbent system has been accepted as the dose $D$; both volumes are in practice the same. Furthermore, it was assumed that the water density $\rho_{w}$ and the system density $\rho_{u}$ are almost the same, thus their ratio

$$
\frac{\rho_{w}}{\rho_{u}}=1
$$

\subsection{ADSORPTION IN A COLUMN SYSTEM}

Transport of adsorbate in an adsorption column can be described by the advection and diffusion equation, taking into account the adsorption rate [16-18]:

$$
\varepsilon \frac{\partial C}{\partial t}+V_{x} \frac{\partial C}{\partial x}=D_{x} \frac{\partial^{2} C}{\partial x^{2}}-k a_{m} \rho_{p, \text { sorb }}\left(C-C_{i}\right)
$$

where: $V_{x}$ - the flow rate, $\mathrm{m} / \mathrm{s}, D_{x}-$ mass dispersion coefficient, $\mathrm{m}^{2} / \mathrm{s}$, both values for the empty bed, $\varepsilon$ - filter bed porosity, $\rho_{p, \text { sorb }}$ - apparent density of the sorbent in a column $\mathrm{g} / \mathrm{m}^{3}, \rho_{p \text {, sorb }}=m_{\text {sorb }} / V, V$ - volume of the adsorption column, $\mathrm{m}^{3}, x$ - coordinate of distance, $\mathrm{m}$, for other symbols, see above.

The mass of adsorbate $a^{*}$ in a fixed adsorption layer, $\mathrm{g} / \mathrm{m}^{3}$, is described by:

$$
\frac{\partial a^{*}}{\partial t}(1-\varepsilon)=k a_{m} \rho_{p, \text { sorb }}\left(C-C_{i}\right)
$$


where

$$
a^{*}=\frac{a \rho_{p, \text { sorb }}}{1-\varepsilon}
$$

To integrate Eqs. (10) and (11), it is necessary to define the adsorption isotherm. In this case, Henry's isotherm has a form:

$$
a^{*}=\Gamma^{*} C_{i}
$$

where $\Gamma^{*}$ is the Henry's coefficient, $\mathrm{m}^{3}$ of water $/ \mathrm{m}^{3}$ of sorbent,

$$
\Gamma^{*}=\frac{\Gamma \rho_{p, \text { sorb }}}{1-\varepsilon}
$$

The set of equations (10) and (11), together with isotherm (12) can be solved numerically [18]. Equation (10) was integrated over the prior decomposition [18]. First, integration was carried out for adsorbate advection, taking into account the adsorption rate. Then integration for mass dispersion was done. Such procedure reduces the distorting effects of numerical diffusion on the calculated concentrations and the amounts of adsorbate. A computer program, developed to calculate mass transport with simultaneous adsorption at unsteady flows and concentrations in open channels, was modified to carry out calculations for a filter bed without adsorption in a lower layer [18]. The program allows one to carry out the calculations for filter beds with varying dispersion and adsorption properties along the column; both flow rates and concentrations of dissolved compounds may also vary in time.

\section{VERIFICATION OF THE ADSORPTION MODEL IN A VOLUME SYSTEM}

Results on adsorption of the organic compounds onto PAC identified by absorbance measurements were used to determine the time dependences of the model parameters (Eq. (6)). Since the concentration of organic compounds $C$ is proportional to absorbance $A$, it was assumed for the concentration $C$. It has been shown that the dynamic adsorption plots of the sorbent system are linear functions of time (Fig. 2). It was assumed that the equilibrium in the solution after $24 \mathrm{~h}$ was described by Henry's isotherm. By minimizing the sum of squared deviations between the adsorbances measured and calculated from Eq. (6), the product $k a_{m}$ was determined. It characterized the rate constant of adsorbate transfer through the water-sorbent interface in hydrodynamic conditions. 
A very good fit of the model (6) to the all measured data was obtained; the squared correlation coefficient was 0.9605 . The replacement mass transfer rate constant $k a_{m}$ for the adsorption process was $1.37 \times 10^{-5}(\mathrm{~m} / \mathrm{s}) \cdot\left(\mathrm{m}^{2} / \mathrm{g}\right.$ of sorbent). Model (6) allows one to simulate operation of continuous flow adsorption units at different volume systems (layouts). It is possible to effectively diminish absorbance to zero value from water $\mathrm{A}$ in less than $200 \mathrm{~s}$ at the PAC dose of $500 \mathrm{~g} / \mathrm{m}^{3}$. The time is comparable to adsorption times observed in filter beds of $0.5 \mathrm{~m}$ high that can be used in real-life technological systems.

\section{VERIFICATION OF THE ADSORPTION MODEL IN THE COLUMN SYSTEM}

Results of studies on adsorption of organic compounds identified by UV absorbance on PAS applied on a anthracite layer were used to determine the model parameters (Eqs. (10)-(12). Solutions (A or B) similar to the solutions used in the volume adsorption studies passed down through the filter column. Minimizing the sum of squared deviations between the all measured absorbances and those calculated from the model, the model parameters such as $D_{x}^{*}=D_{x} / \varepsilon, k_{C}=k a_{m} \rho_{p \text {, sorb }} / \varepsilon$, and $\Gamma^{*}$ have been determined. A fitting error for water A was $7.0 \%$ (Fig. 7) while for water B it was $10.2 \%$ (Fig. 8). In both cases, the longitudinal dispersion coefficients $D_{x}^{*}$ were significant, if compared to the theoretical values (Figs. 7 and 8) [20]. This is due to a low ratio of the column diameter to the diameter of a filter medium particles. A higher dispersion coefficient for water $\mathrm{A}$ is also associated with suspended solids present in the filtered water (turbidities for water A and B were 1.2 NTU and 0.1 NTU, respectively) and their retention within the adsorption layer; this way a higher flow rate through the filter was observed. For water A, the Henry constants $\Gamma$, calculated from Eq. (13) based on $\Gamma^{*}$, are approximately 1.8 times lower than $\Gamma$ determined from beaker tests for the adsorption time $24 \mathrm{~h}$ (Figs. 2 and 7). It can be explained by: limitations of Henry's isotherm at high concentrations, separation of organic substances with different affinity for PAC, etc., In the case of water B (lower initial absorbance) Henry's constant was comparable to the one determined in the beaker test after $24 \mathrm{~h}$ of adsorption. It can be explained by the fact that Henry's isotherm describes better the adsorption equilibrium at lower concentrations of organics.

The mass transfer rate constant $k_{C}$ at the adsorption process for water A (Fig. 7) is not much lower than that determined for water B (Fig. 8) due to retention of suspended solids within the filtering material while filtering water $\mathrm{A}$ and a subsequent lower diffusion rate. The replacement constant $k a_{m}$, determined from $k_{C}$ (Fig. 7) for water A, was $3.60 \times 10^{-6}(\mathrm{~m} / \mathrm{s}) \cdot\left(\mathrm{m}^{2} / \mathrm{g}\right.$ of sorbent) and was 3.8 times lower than the replacement constant determined for the volume adsorption. It can be explained by the fact that PAC particles stick together and form multiple adsorption layers on the surface of anthracite. 
This way the outer surface of the effective mass transfer between the aqueous phase and the sorbent is reduced.

\section{PROCESS SIMULATION}

Model (10)-(12) enabled simulation of the filtration and adsorption process in the twolayer filter bed. High dispersion shows a negative impact on adsorption in column systems. For comparison, additional simulations were performed for the dispersion coefficient ten times lower than the determined one (Fig. 7, curve (2), $D_{x}^{*}=20.92 \times 10^{-5} \mathrm{~m}^{2} / \mathrm{s}$, curve (10) $\left.D_{x}^{*}=2.092 \times 10^{-5} \mathrm{~m}^{2} / \mathrm{s}\right)$. As was expected, a lower dispersion resulted in a higher process efficiency (lower absorbance in the column effluent at the same time, see Fig. 7, curves (2) and (10)). Similar promising results have been obtained when a thicker adsorption layer was used $(0.60 \mathrm{~m}$ instead of $0.38 \mathrm{~m})$ with the same PAC mass per unit volume (Fig. 7, curves (2) and (7)). An additional increase of the column efficiency is possible for a lower dispersion within the system and a thicker adsorption layer (Fig. 7, curves (2), (6), (7) and (10)). Lower dispersion can be achieved by a smaller diameter of the filter medium [20].

The results of simulations (Fig. 7) enabled one to determine organic compounds (identified by absorbance) captured in the filter and remaining in the filter effluent until the absorbance reached $5 \mathrm{~m}^{-1}$ (Table 2).

Table 2

Process parameters and efficiency in the column/volume systems

\begin{tabular}{|c|c|c|c|c|}
\hline Simulation number & 2 & 10 & 7 & 6 \\
\hline Height of adsorption layer, $\mathrm{m}$ & 0.38 & 0.38 & 0.6 & 0.6 \\
\hline Mass of PAC per unit volume of the filter, $\mathrm{kg} / \mathrm{m}^{3}$ & 8.26 & 8.26 & 12.4 & 12.4 \\
\hline Filtration rate (empty bed), $\mathrm{m} / \mathrm{h}$ & 6.00 & 6.00 & 6.00 & 6.00 \\
\hline Column operation time, $\mathrm{h}$ & 13.8 & 15.6 & 23.7 & 25.5 \\
\hline Filtrate volume, $\mathrm{m}^{3}$ & 82.8 & 93.6 & 142.2 & 153.8 \\
\hline Average UV absorbance at $254 \mathrm{~nm}$ in filtrate, $\mathrm{m}^{-1}$ & 2.71 & 2.32 & 2.34 & 1.86 \\
\hline Amount of adsorbate removed onto PAC $a_{1}$ in a column system, $\mathrm{m}^{3} /(\mathrm{g} \cdot \mathrm{m})$ & 0.119 & 0.148 & 0.149 & 0.172 \\
\hline Amount of adsorbate $a_{2}$ removed onto PAC in a volume system, $\mathrm{m}^{3} /(\mathrm{g} \cdot \mathrm{m})$ & 0.076 & 0.065 & 0.066 & 0.052 \\
\hline$a_{1} / a_{2}$ & 1.6 & 2.3 & 2.3 & 3.3 \\
\hline
\end{tabular}

Next, the average adsorbate amounts $a_{1}$ of PAC in a column system were determined (Table 2). Based on the dynamic isotherm (adsorption time of $0.5 \mathrm{~h}$ ), the amounts of adsorbate $a_{2}$ were determined in volume systems with adsorption following coagulation and sedimentation (Table 2). They were determined for the states when the average absorbance over time in the column was equal to absorbance after $0.5 \mathrm{~h}$ of adsorption in volume systems. The results (Table 2, water A) show that sorbent utilization in 
the column system is from 1.6 to 3.3 times greater than its utilization in the volume systems.

Based on the simulation calculations it can be concluded that dispersion in full/technical scale applications would be at least ten times lower than in a laboratory model and therefore it would be possible to further increase PAC absorption efficiency.

\section{CONCLUSIONS}

A new method of adsorption on PAC deposited on the filter bed has been developed. The method may be used for continuous or occasional removal of organic substances from water or industrial wastewater. The method can be employed in the existing installations, where filtration has been used. The main conclusions are as follows:

- In a two-layer filter bed PAC should be applied onto a top layer, while in a three-layer filter bed onto a middle layer.

- PAC utilization in volume dispersion systems is lower than in column systems with a fixed sorbent bed.

- Comparative technological studies confirmed that absorption efficiency in the column system was several times higher than that in the volume system.

- An advection/dispersion mathematical model with simultaneous adsorption was developed for filters supported with PAC. The model was positively verified in dynamic conditions.

- The model allows one to simulate the filter operation for different geometrical and hydraulic parameters of the filter bed.

- The model is a good tool in designing the filters supported with PAC.

\section{REFERENCES}

[1] Regulation of the Minister of the Environment Acts, Laws 2006, No. 137, Item 984, on the conditions to be met when sewage is discharged into water or soil and on substances particularly harmful to the aquatic environment, as amended in Act. Laws 2009, No. 27, Item 169.

[2] Adamski W., Szlachta M., Water Treatment Technology. Principles and Modeling, Wrocław University of Technology, Wrocław 2011.

[3] Wastewater Engineering. Treatment and Reuse, Metcalf \& Eddy, Inc., McGraw Hill, 2004.

[4] Ina K., Joll C., Heitz A., Powdered activated carbon coupled with enhanced coagulation for natural organic matter removal and disinfection by-product control. Application in a Western Australian water treatment plant, Chemosphere, 2011, 83, 661.

[5] NAJM I.N., SNOEYINK V.L., LyKInS B.W., ADAms J.Q., Using powdered activated carbon. A critical review, JAWWA, 1991, 83 (1), 65.

[6] SANdrucci P., Merlo G., GenON G., Meucci L., PAC activity vs. by-product precursors in water disinfection, Water Res., 1995, 29 (10), 2299.

[7] Newcombe G., Morrison J., Hepplewhite C., Simultaneous adsorption of MIB and NOM onto activated carbon. I. Characterization of the system end NOM adsorption, Carbon, 2002, 40 (12), 2135. 
[8] Newcombe G., Morrison J., Hepplewhite C., Knappe D.R.U., Simultaneous adsorption of MIB and NOM onto activated carbon. II. Competitive effects, Carbon, 2002, 40 (12), 2147.

[9] FABRIS R., ChOW C.W.K., DRIKAS M., Practical application of a combined treatment process for removal of recalcitrant NOM - alum and PAC, Water Sci. Technol., Water Supply, 2004, 4 (4), 89.

[10] Uyak V., Yavuz S., Toroz I., Ozaydin S., Genceli E.A., Disinfection by-products precursors removal by enhanced coagulation and PAC adsorption, Desalination, 2007, 216 (1-3), 334.

[11] Carriere A., Vachon M., Belisle J.-L., Barbeau B., Supplementing coagulation with powdered activated carbon as a control strategy for trihalomethanes: application to an existing utility, J. Water Supply. Res. Technol., 2009, 58 (5), 363.

[12] Szlachta M., ADAmSKi W., Application of adsorption on powdered active carbon for the removal of dissolved organic substances from surface water, Ochr. Środ., 2009, 31 (2), 61.

[13] Szlachta M., AdAMSKi W., Mathematical model of PAC adsorption and its application in water technology, Environ. Prot. Eng., 2008, 34 (2), 5.

[14] SZLACHTA M., ADAMSKI W., Empirical formulae for efficiency of DOM removal by adsorption determined on the basis of bench-scale results, Pol. J. Environ. Stud., 2009, 18 (3), 481.

[15] WiLIMAŃSKi K., A new method for organic matter removal from groundwater via powdered active carbon, Ochr. Środ., 2005, 27 (3), 13 (in Polish).

[16] Coulson J.M., Richardson J.F., Coulson and Richardson's Chemical Engineering. Vol. 1. Fluid Flow, Heat Transfer and Mass Transfer, Elsevier, 1999.

[17] BIELSKI A., Modelling of mass transport in watercourses considering mass transfer between phases in unsteady states. Part II. Mass transport during absorption and adsorption processes, Environ. Prot. Eng., 2011, 37 (4), 71.

[18] BIELSKI A., Modelling of mass transport in watercourses at unsteady states, Environ. Prot. Eng., 2012, $38(3), 159$.

[19] Gryfskand Hajnówka - manufacturer of activated carbons, http://gryfskand.pl/

[20] BATU V., Applied flow and solute transport modeling in aquifers, Taylor \& Francis Group, 2006. 